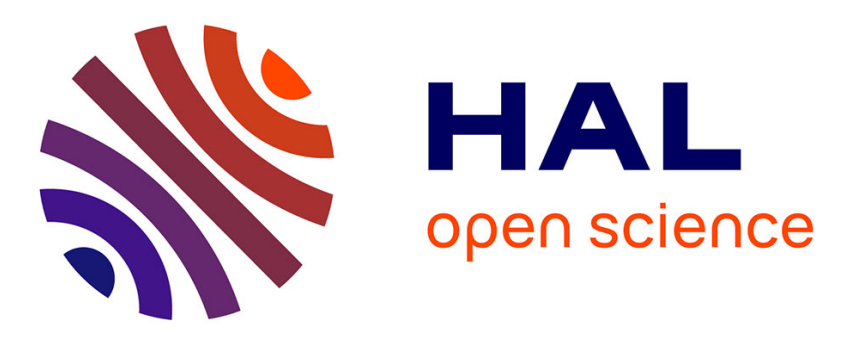

\title{
Real time and label-free analysis of cellular activity on chip
}

Sarah Milgam, Thierry Livache, Yoann Roupioz, Sandra Cortes, Marie-Bernadette Villiers, Patrice N. Marche

\section{- To cite this version:}

Sarah Milgam, Thierry Livache, Yoann Roupioz, Sandra Cortes, Marie-Bernadette Villiers, et al.. Real time and label-free analysis of cellular activity on chip. IEEE SENSORS 2009 Conference, Oct 2009, Canterbury, New Zealand. pp.1768 - 1771, 10.1109/ICSENS.2009.5398465 . inserm-00509441

\section{HAL Id: inserm-00509441 https://www.hal.inserm.fr/inserm-00509441}

Submitted on 23 Aug 2010

HAL is a multi-disciplinary open access archive for the deposit and dissemination of scientific research documents, whether they are published or not. The documents may come from teaching and research institutions in France or abroad, or from public or private research centers.
L'archive ouverte pluridisciplinaire $\mathbf{H A L}$, est destinée au dépôt et à la diffusion de documents scientifiques de niveau recherche, publiés ou non, émanant des établissements d'enseignement et de recherche français ou étrangers, des laboratoires publics ou privés. 


\section{Real time and label-free analysis of cellular activity on chip}

\author{
S. Milgram, T. Livache, Y. Roupioz \\ CREAB \\ UMR 5819 SPrAM (CEA-CNRS-UJF) \\ Grenoble, France \\ Yoann.roupioz@cea.fr
}

\author{
S. Cortes, M-B. Villiers, P.N. Marche \\ Laboratoire d'immunochimie \\ INSERM U548, Université J. Fourier \\ Grenoble, France
}

\begin{abstract}
Biochips for cellular applications are of considerable interest to both fundamental research and diagnostic fields. In this study, we demonstrate the use of Surface Plasmon Resonance imaging (SPRi) for the analysis of blood cell activity on biochip. This method previously used to detect antigen-antibody interactions was adapted for the detection of antibodies secreted from B-cell hybridoma using specific antigens grafted on the chip by electropolymerization. For the first time, living cells were maintained in culture on the biochip and the kinetic of their secretion was monitored by SPRi. Unlike traditional methods such as ELISA or ELISPOT, this novel technique permits a realtime and label-free analysis. As a result, antibodies secreted were detected only few minutes after the loading of cells on the chip. Thus, this sensor provides a promising tool for cells phenotype analysis and could be useful in analyzing other secreting cells, like T-cells, widely involved in the inflammatory response and several pathologies.
\end{abstract}

\section{INTRODUCTION}

The miniaturization of biosensors, allowing a rapid analysis of small sample volumes, has generated a considerable interest in the diagnostic and clinical research which involves biological samples both rare and delicate. Several studies address this topic, developing microarrays for the direct analysis of live cells [1]. Blood analysis is crucial in these fields. Phenotype and secretory activities of blood cells are specially studied to characterize immune responses. In these aim, capture and characterization of living lymphocytes have been developed on a miniature cytometry plateform [2]. Other studies deal with microarrays specially dedicated to the detection of cellular metabolites [3, 4]. However, these methods, as other traditional techniques for detecting secreted metabolites, involve fluorescent staining and end-point analysis.

Label-free analysis is possible using other detection system like Surface Plasmon Resonance imaging (SPRi). SPR-based sensors have previously been used to detect interactions between many different types of molecules like DNA, peptide or protein $[5,6]$. More recently, this method was used to detect live cells [7, 8]. In this way, Localized Surface Plasmon Resonance (LSPR) and Grating-Coupled Surface Plasmon
Resonance imaging (GCSPRi) allow the label-free detection of specific cells or cellular metabolites $[9,10]$.

Although label-free analysis was demonstrated in these studies, there is no method described in literature that allows a real-time analysis of cell secreted products. In this study, we developed a new miniature sensor for cell analysis in a both label free and real-time manner. The experimental setup using SPRi as detection method was adapted to maintain B-cell hybridomas in culture on chip and detect antibodies secreted from these cells (Fig. 1).

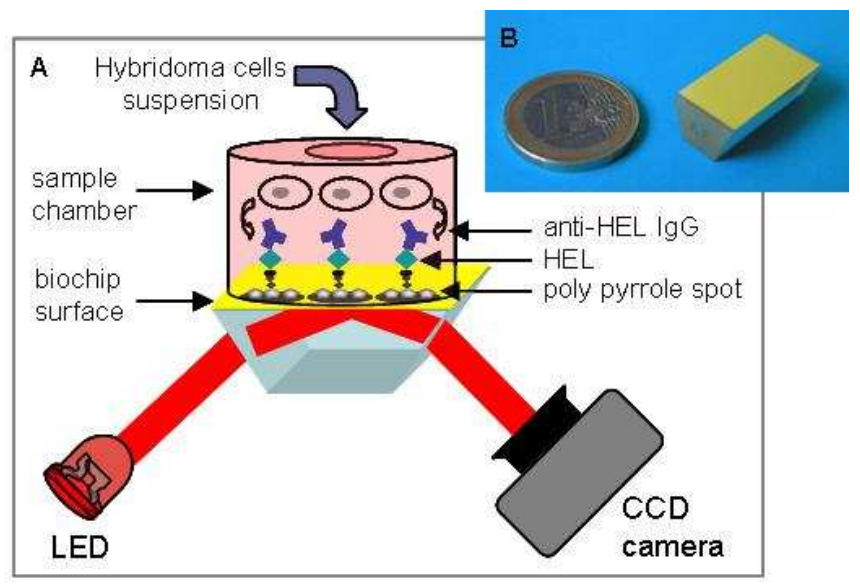

Figure 1. (A) Scheme of the SPR imaging setup.(B) Photograph of a goldcoated chip.

\section{MATERIALS AND METHODS}

\section{A. Biochip preparation}

Prisms bearing a gold surface (50nm thick) (Fig. 1b) were provided by GenOptics (Orsay, France) and prepared as described previously [5].

N-hydroxysuccinimidyl 6-(pyrrol-yl)-caproate (NHSpyrrole) were prepared as previously described [6] and conjugated to proteins in phosphate-buffered saline (PBS) $\mathrm{pH}$ 7,4 overnight at $4^{\circ} \mathrm{C}$ using NHS-pyrrole/protein molar ratio of 10. Conjugated proteins were then purified by 
ultracentrigugation on $3 \mathrm{kDa}$ MWCO membranes and diluted at different concentration $(5,10$ or $20 \mu \mathrm{M})$ in spotting buffer (50mM phosphate buffer, $50 \mathrm{mM} \mathrm{NaCl}$ and $10 \%$ glycerol, $\mathrm{pH}$ 6.8) containing $20 \mathrm{mM}$ of free pyrrole. Proteins were then grafted on chip by electrocopolymerization of free pyrrole and pyrrole-modified protein (100ms, $2 \mathrm{~V} \mathrm{ddp).}$

\section{B. Cells culture}

The mouse hybridoma cell line F10 producing monoclonal anti-lysozyme (anti-HEL) [11] was grown in DMEM supplemented with $10 \%$ fetal bovine serum, non-essential amino acids $\left(0.1 \mathrm{mM} \cdot \mathrm{mL}^{-1}\right)$, sodium pyruvate $\left(1 \mathrm{mM} \cdot \mathrm{mL}^{-1}\right)$, $50 \mu \mathrm{M}$ 2-mercaptoethanol, $50 \mathrm{U} / \mathrm{mL}$ penicillin and $50 \mathrm{mg} \cdot \mathrm{mL}^{-1}$ streptomycin. The cultures were incubated at $37^{\circ} \mathrm{C}$ in a humidified $5 \% \mathrm{CO}_{2}$ incubator. Cells were centrifuged 5 minutes at $200 \mathrm{~g}$ prior to the experiments and the cell pellets were resuspended at $5.10^{5}$ cells. $\mathrm{mL}^{-1}$ in serum-free RPMI medium buffered with Hepes at $28 \mathrm{mM}$.

\section{ELISA titration of anti-HEL IgG secreted by hybridoma cells}

Secretory activities of cells used during SPRi experiment were characterized by ELISA assay. Samples of cellular suspension were incubated at $37^{\circ} \mathrm{C}$ in 24 -well plate. At different times, the supernatant was collected and anti-HEL immunoglobulin $\mathrm{G}$ (IgG) secreted from cells were quantified by ELISA.

Plates were coated with HEL $10 \mu \mathrm{g} \cdot \mathrm{mL}^{-1}$ in PBS for $2 \mathrm{~h}$ at $37^{\circ} \mathrm{C}$. The ELISA was performed as described by Villiers et al. [12] and bound antibodies were revealed with peroxidaseconjugated rabbit anti-mouse $\operatorname{IgG}$ (Sigma) using TMB (3,3',5,5'-tetramethylbenzidine) as substrate. Standard curves were established using purified monoclonal anti-HEL antibody F10.

\section{SPRi detection of antibody secretion}

Cells incubations were carried out at $37^{\circ} \mathrm{C}$ in a peek chamber held in place on the chip (Fig. 1). After saturation of the chip surface with RPMI supplemented with $10 \%$ foetal bovine serum, B-cells hybridomas suspended in serum-free medium were loaded onto the chamber and their secretory activity was monitored by SPRi. Protein-protein interactions of the secreted IgG and the sensor grafted antigen on the chip surface induce a variation of the refractive index near the gold surface, triggering a variation of reflectivity monitored using a 12-bit CCD [5].

\section{E. Fluorescent detection of antigen-antibody interaction}

At the end of the SPRi experiment, the biochip was washed in PBS. IgG bound to the chip were revealed with a biotinylated anti-mouse antibody, followed by a StreptavidinPhycoerythrin conjugation step. Fluorescence was observed using an epi-fuorescence microscope (BX, Olympus) equipped with Peltier cooled CCD camera.

\section{RESULTS AND DISCUSSION}

B-cell hybridoma F10 was chosen for its ability to secret monoclonal anti-HEL IgG. Biochips were functionalized by electropolymerization using HEL-pyrrole conjugate solution at 5,10 or $20 \mu \mathrm{M}$. Cytochrome $\mathrm{C}$ was chosen as a negative controle because of its molecular weigh close to that of HEL. The control spots corresponding without HEL were made from a solution of electropolymerisation containing $20 \mu \mathrm{M}$ of cytochrome C-pyrrole conjugate, in order to have a steric hindrance similar to that of HEL spots. Cells were loaded in the sample chamber as described in Fig. 1. Binding between HEL antigen grafted on the chip and anti-HEL IgG secreted from cells was detected by SPRi and the kinetic of cellular secretion was recorded for eight hours by both SPRi and ELISA titration of cellular supernatants.

A reflectivity variation can be observed in real time on the SPRi image only few minutes after cells injection (Fig. 2A).

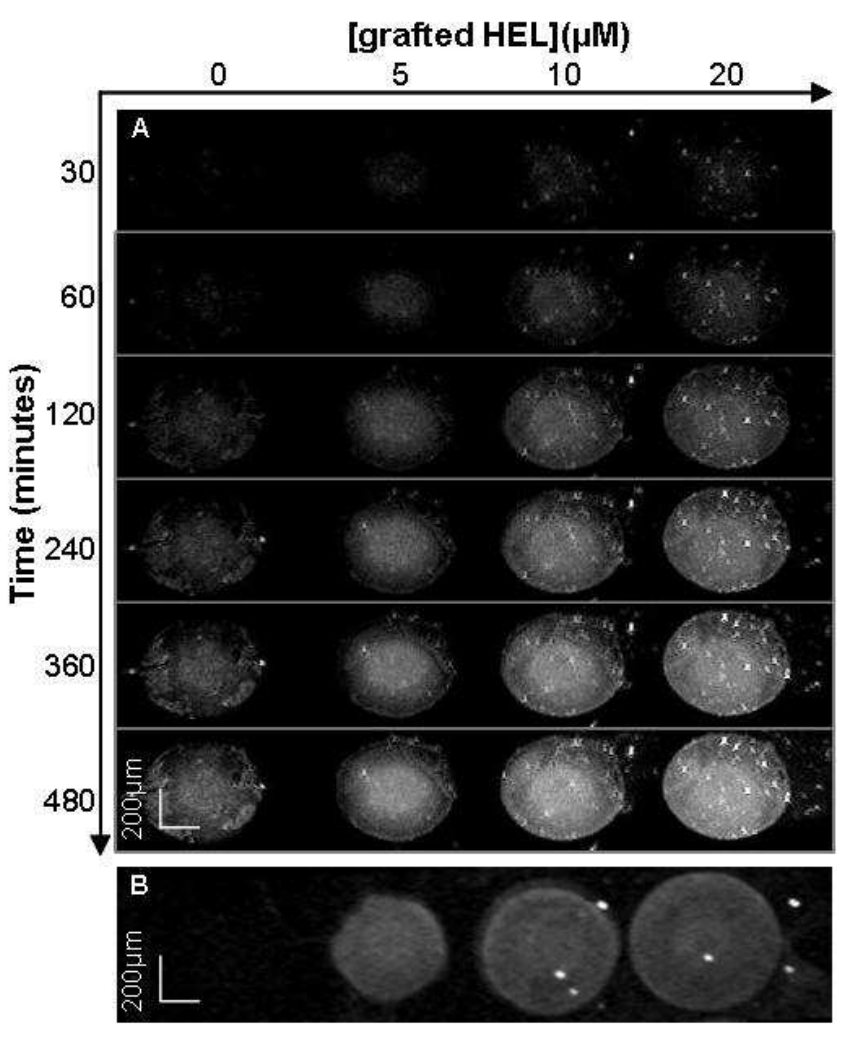

Figure 2. (A) SPR image of a biochip containing HEL spots $(5,10$ or $20 \mu \mathrm{M})$ or cytochromeC control spot (HEL $0 \mu \mathrm{M}$ ) after different times of exposure to secreting cells. (B) Image of the same spots observed at the end point of the experiment by fluorescence microscopy after staining with antimouse IgG ( $\mathrm{Fc}$ specific).

Thanks to the imaging setup, reflectivity variations of the surface were observed and the averaged grey level of pixels 
contained in the image of HEL spots were shown to increase overtime. These direct observations were plotted to allow comparison within all the samples spotted on the biochip (Fig. 3A).

The specificity of the reaction was verified thanks to the cytochrome $\mathrm{C}$ control spots. No reflectivity variation was observed on these spots. This specificity was also confirmed at the end of the experiment by counter staining of the chip surface with anti-mouse IgG biotin conjugate followed by a Streptavidin-Phycoerythrin conjugation step. It revealed a very specific labeling of the HEL spots (Fig. 2B).
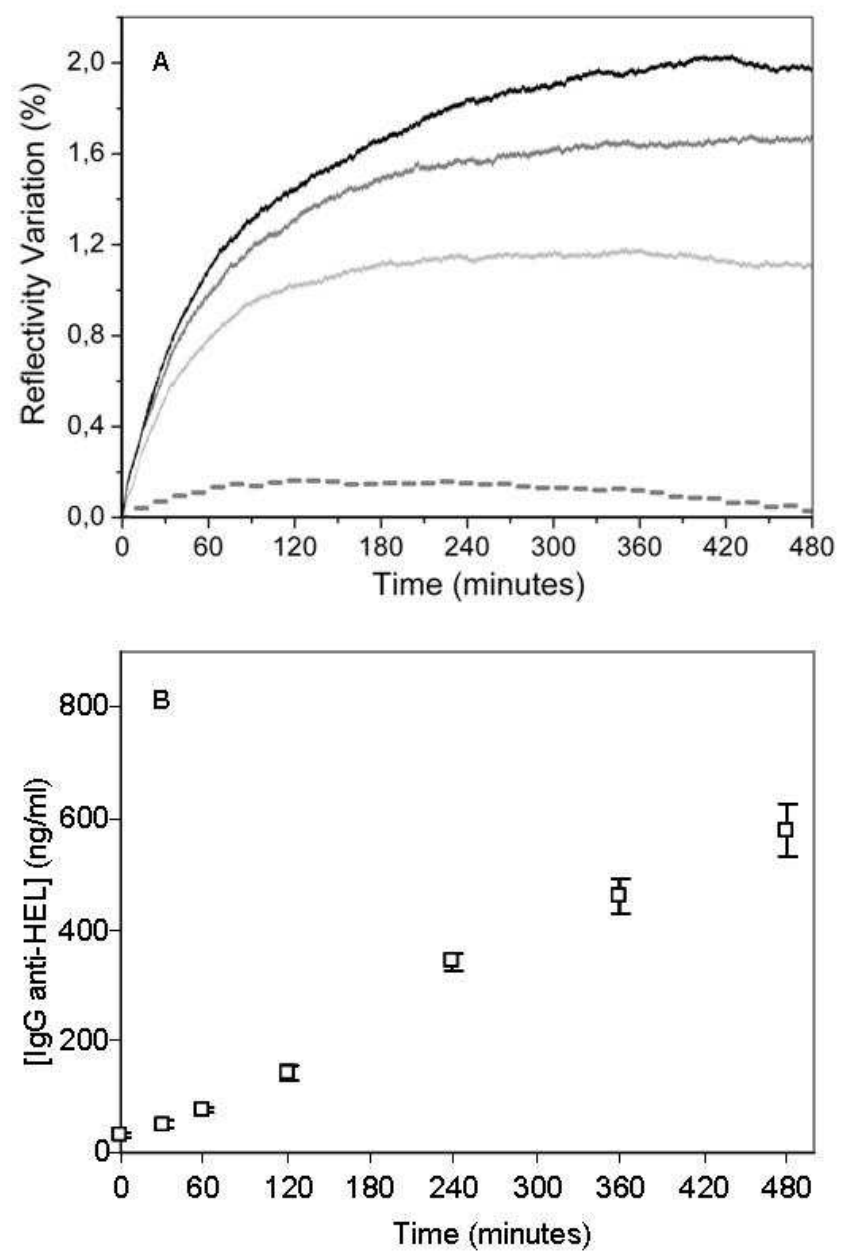

Figure 3. (A) SPR monitoring of the reflectivity variations of different spots functionalized with Cytochrome C $20 \mu \mathrm{M}$ (gray dotted line), HEL $5 \mu \mathrm{M}$ (light gray line), $10 \mu \mathrm{M}$ (dark gray line) or $20 \mu \mathrm{M}$ (black line). Cells were loaded on chip at time 0 . (B) ELISA titration of anti-HEL IgG secreted by cells in culture medium at different times.

On the other hand, anti-HEL IgG released from B-cells were titrated by ELISA (Fig. 3B). After 30 minutes of incubation, the concentration of IgG in cellular supernatant was
$51.3 \pm 5.6$ ng. $\mathrm{mL}^{-1}$ and increased linearly with the time reaching a concentration of $579.1 \pm 47.7 \mathrm{ng} \cdot \mathrm{ml}^{-1}$ after eight hours of incubation.

ELISA was used as a reference technique for titration of cellular metabolites. It allowed the characterisation of secretory activity of F10 hybridoma cells in our experimental conditions. Moreover, ELISA results can be compared to SPRi results in order to evaluate the efficiency of SPRi-based sensor detection method.

Firstly, these results allowed to verify that the secretory activity of B-cells is correctly maintained in our experimental conditions. Besides, when we compare both types of results, a difference of shape was observed between both curves. In the case of ELISA, the time-course curve obtained was linear. The SPRi curves, unlike the ELISA curve, showed a signal increase much higher for short incubation times, with a slope much greater than for ELISA curves. In a second time, the SPRi slopes decreased and reached a plateau. This phenomenon can be explained by the intrinsic nature of the detection system: the surface is functionalized with a finite number of antigen molecules which can be seen as vacant sites. Interactions taking place on the surface are directly linked to the vacant site densities and thus explain the differences of plateau levels when almost all vacant sites are occupied. The saturation of spots in our experiments was verified by injection of purified IgG anti-HEL at the end of the experiment. No increase of reflectivity was observed, signifying that spots are well saturated (data not shown).

Another interesting feature is the low concentration of metabolites titrated by ELISA in supernatant after thirty minutes incubation. At this time, a great specific SPR signal was observed and ELISA results indicated a concentration of about 50 ng. $\mathrm{mL}^{-1}$ of secreted anti-HEL IgG, corresponding to $0.35 \mathrm{nM}$ in bulk medium. In classical SPRi experiments studying molecular interaction, the typical detection limit is about $10 \mathrm{nM}$. Thus, IgG in solution at $0.3 \mathrm{nM}$ should not be detected with a classic SPRi detection system. In our case, live secreting cells are directly loaded onto the sensor and sediment near the gold surface. The local exploration of secreted proteins in the intimate vicinity of the cells gives access to locally high concentrations of secreted products. The localization of cells close to the chip surface allowed us to access to protein concentrations above the SPR current LOD and thus showed the performance of SPR-based sensors for cellular secretion detection.

Thus, in our conditions, the secretory activity of B-cells can be detected by SPRi with a good specificity and with sensitivity better than ELISA for early cellular activities.

\section{CONCLUSION}

To conclude, we shown that our method allows detect very quickly metabolites secreted from cells, maintaining cells in culture on chip without loss of their activity. 
The techniques routinely used involve most often several steps of analysis: collection of cells, lysis or fixing of them, immunostaining with different steps of wash and staining, and finally, observation. For the first time, we propose a one-step imaging method able to detect in real time and without label secretory activity of live cells. Moreover, the system shows a great flexibility and could be adapt to multiparametric detection, allowing simultaneous analysis of different metabolites. This quick and easy method could be a tool very useful for cell phenotype analysis. Currently, the SPR-based sensor is being adapted for the study of T-cells behaviour.

\section{REFERENCES}

[1] D. S. Chen and M. M. Davis, "Molecular and functional analysis using live cell microarrays," Current Opinion in Chemical Biology, vol. 10, pp. 28-34, 2006.

[2] H. Zhu, M. Macal, C. N. Jones, M. D. George, S. Dandekar, and A. Revzin, "A miniature cytometry platform for capture and characterization of T-lymphocytes from human blood," Analytica Chimica Acta, vol. 608, pp. 186-196, 2008.

[3] C. N. Jones, J. Y. Lee, J. Zhu, G. Stybayeva, E. Ramanculov, M. A. Zern, and A. Revzin, "Multifunctional protein microarrays for cultivation of cells and immunodetection of secreted cellular products," Anal Chem, vol. 80, pp. 6351-7, Aug 152008.

[4] H. Zhu, G. Stybayeva, M. Macal, E. Ramanculov, M. D. George, S. Dandekar, and A. Revzin, "A microdevice for multiplexed detection of T-cell-secreted cytokines," Lab Chip, vol. 8, pp. 2197-205, Dec 2008.

[5] P. Guedon, T. Livache, F. Martin, A. Roget, G. Bidan, and Y. Levy, "Characterization and optimization of a real-time, parallel, label-free, polypyrrole-based DNA sensor by surface plasmon resonnance imaging.," Analytical Chemistry, vol. 72, pp. 60036009,2000

[6] L. Grosjean, B. Cherif, E. Mercey, A. Roget, Y. Levy, P. N. Marche, M.-B. Villiers, and T. Livache, "A polypyrrole protein microarray for antibody-antigen interaction studies using a labelfree detection process," Analytical Biochemistry, vol. 347, pp. 193-200, 2005.

[7] M. Hide, T. Tsutsui, H. Sato, T. Nishimura, K. Morimoto, S. Yamamoto, and K. Yoshizato, "Real-Time Analysis of LigandInduced Cell Surface and Intracellular Reactions of Living Mast Cells Using a Surface Plasmon Resonance-Based Biosensor," Analytical Biochemistry, vol. 302, pp. 28-37, 2002.

[8] E. Suraniti, E. Sollier, R. Calemczuk, T. Livache, P. N. Marche, M.-B. Villiers, and Y. Roupioz, "Real-time detection of lymphocytes binding on an antibody chip using SPR imaging," Lab Chip, vol. 7, pp. 1206-08, 2007.

[9] T. Endo, S. Yamamura, K. Kerman, and E. Tamiya, "Label-free cell-based assay using localized surface plasmon resonance biosensor," Analytica Chimica Acta, vol. 614, pp. 182-189, 2008.

[10] G.-b. Jin, D. W. Unfricht, S. M. Fernandez, and M. A. Lynes, "Cytometry on a chip: Cellular phenotypic and functional analysis using grating-coupled surface plasmon resonance," Biosensors and Bioelectronics, vol. 22, pp. 200-206, 2006.
[11] D. Tello, F. A. Goldbaum, R. A. Mariuzza, X. Ysern, F. P. Schwarz, and R. J. Poljak, "Three-dimensional structure and thermodynamics of antigen binding by anti-lysozyme antibodies," Biochem Soc Trans, vol. 21, pp. 943-6, Nov 1993.

[12] M.-B. Villiers, F. M. Gabert, M. R. Jacquier, C. L. Villiers, and M. G. Colomb, "Involvement of the $\mathrm{Zn}$-Binding region of tetanus toxin in $\mathrm{B}$ and $\mathrm{T}$ recognition. Influence of $\mathrm{Zn}$ fixation," Molecular Immunology, vol. 30, pp. 129-136, 1993. 